\title{
DEVELOPING PRESCHOOL CHILDREN'S COMPUTATIONAL THINKING WITH EDUCATIONAL ROBOTICS: THE ROLE OF COGNITIVE DIFFERENCES AND SCAFFOLDING
}

\author{
Kyriakoula Georgiou and Charoula Angeli \\ Department of Education, University of Cyprus, Dramas 11-13, 1678, Nicosia, Cyprus
}

\begin{abstract}
The development of computational thinking is as important as writing, reading and arithmetic, and, it should start as early as kindergarten (Wing, 2008). However, little has been done in terms of investigating the factors influencing the development of computational thinking in preschool education (Bers et al., 2014; Ching et al., 2018; Kazakoff et al., 2013; Sullivan et al., 2013). Accordingly, the study herein investigated how young children's computational thinking could be developed using the Bee-Bot and two scaffolding techniques, while children's field-dependence/independence (FDI) was taken into consideration. The study has practical significance for classroom teachers, as they can use the results of this research to integrate the teaching of computational thinking skills in their lessons.
\end{abstract}

\section{KEYWORDS}

Computational Thinking, Cognitive Types, Scaffolding, Educational Robotics, Young Children

\section{INTRODUCTION}

The development of computational thinking is as important as writing, reading and arithmetic, and, it should start as early as kindergarten (Wing, 2008). However, little has been done in terms of investigating the factors influencing the development of computational thinking in preschool education (Bers et al., 2014; Ching et al., 2018; Kazakoff et al., 2013; Sullivan et al., 2013).

Accordingly, the study herein investigated how young children's computational thinking could be developed using the Bee-Bot and two scaffolding techniques, while children's field-dependence/independence (FDI) was taken into consideration. The study has practical significance for classroom teachers, as they can use the results of this research to integrate the teaching of computational thinking skills in their lessons.

\section{THEORETICAL FRAMEWORK}

\subsection{Field-Dependence/Independence (FDI)}

FDI reflects the ways in which individuals perceive and process information from their surrounding environment (Evans, Richardson, \& Waring, 2013; Witkin, Moore, Goodenough, \& Cox, 1977). FDI is differentiated from learning styles in that learning styles are self-reported accounts of individuals' instructional preferences across specific domains and tasks (Messick, 1987). Witkin et al. (1977) conceptualized FDI as a bipolar construct with two distinct modes of perception, namely, field-dependence (FD) and field-independence (FI). FI learners have been characterized as analytical, and visually perceptive, while FD learners have been referred to as global and not visually perceptive (Hall, 2000). FDI is a relevant construct to consider in this study, because there is systematic evidence showing that it plays a significant role in students' learning during problem-solving activities with various technological tools (Angeli, 2013; Angeli \& Valanides, 2004a, 2009, 2013; Chen \& Macredie, 2004). 


\subsection{Computational Thinking}

Grover and Pea (2013) concluded that researchers have come to accept that computational thinking is a thought process that utilizes the elements of abstraction, generalization, decomposition, algorithmic thinking and debugging (detection and correction of errors). Of particular interest to this study are the skills of algorithmic thinking and debugging. Sequencing (i.e., planning an algorithm, which involves putting actions in the correct sequence), and flow of control (i.e., the order in which individual instructions or steps in an algorithm are evaluated) are considered important elements of algorithmic thinking. Debugging is the skill to recognize when actions do not correspond to instructions, and the skill to fix errors (Bers et al., 2014).

\section{RESEARCH PURPOSE AND HYPOTHESIS}

While the Bee-Bot constitutes an easy to use tool with young children, at the same time, it does not provide a visual representation of the commands that children use to program it, debilitating this way their ability to remember and reflect on their algorithm. This weakness of Bee-Bot creates a need for finding effective ways in order to appropriately scaffold children's learning with the Bee-Bot. To this end, the authors developed and investigated the effectiveness of two scaffolding techniques on FD and FI children's computational thinking skills during problem-solving activities with the Bee-Bot, and, hypothesized that scaffolding and FDI will both play a significant role in children's problem-solving performance.

\section{METHOD}

\subsection{Participants}

The participants were 180 children, 82 females and 98 males, from nine public preschools. The children were five to six years old, and permission was granted from their parents who signed consent forms prior to their children's participation in the study. All children who participated in the study had no previous experience with the Bee-Bot or robotics in general. Children were first classified into FD or FI learners, and, subsequently, each group of FD and FI learners was randomly clustered into two experimental groups that used two different scaffolding strategies (type A and B) and, a control group. As a consequence six equivalent groups were formed since children were categorized based on their cognitive style (FI and FD) and different scaffolding systems (External memory system A, External memory system B and Control Group) with thirty participants in each group as Table 1 shows.

Table 1. Synthesis of the three groups of participants based on the number of the students; their gender and individual characteristics

\begin{tabular}{|c|c|c|c|}
\hline Groups & Participants & & \\
\hline \multirow[t]{2}{*}{ Control Group } & 60 & Boys & Girls \\
\hline & & 37 & 23 \\
\hline \multirow[t]{2}{*}{ Scaffolding type A } & 60 & Boys & Girls \\
\hline & & 35 & 25 \\
\hline \multirow[t]{2}{*}{ Scaffolding type B } & 60 & Boys & Girls \\
\hline & & 26 & 34 \\
\hline Total & 180 & 96 & 82 \\
\hline
\end{tabular}




\subsection{Research Instruments}

\subsubsection{Children's Embedded Figures Test (CEFT)}

The CEFT (Karp \& Konstadt, 1971) has an internal credibility of Cronbach's $\alpha=0.87$. It is specially designed to identify the cognitive type of children aged from five to nine years old. It includes 38 shapes in which smaller shapes like a triangle $(\triangle)$ and a small house $(\neg)$ are hidden in them. Participants are instructed to discover the hidden shapes in the more complex ones having at their disposal thirty seconds for each shape. The total administration time for the test is $20 \mathrm{~min}$. One point is given for each shape correctly recognized. The maximum score on the test is 20 points.

\subsection{Research Materials}

\subsubsection{Problem-solving Tasks}

Children were engaged in a series of problem-solving tasks in order to program the Bee-Bot to move from one place to another. The first problem-solving task consisted of thirteen subtasks while the other two problem-solving tasks consisted of five subtasks. The subtasks were designed and presented to each child in increasing levels of complexity (Armoni \& Gal-Ezer, 2014). Children were allowed twenty minutes for each problem-solving task. The tasks were developed by the researchers of this study and were checked for internal validity by two experts in computational thinking who discussed and resolved all disagreements.

\subsubsection{Bee-Bot}

The Bee-Bot is a programmable floor robot suitable for children of three to eight years old. The Bee-Bot can store a maximum of forty commands in its memory. It consists of seven keys that enable the Bee-Bot to move forward and backward, to turn left or right by 90 degrees, to clear its memory, to pause, and to GO, that is to execute a sequence of commands.

\subsubsection{Bee-Bot Mats}

Bee-Bot mats are surfaces, as shown in Figure 1, made of durable plastic. Each surface is organized into squares of $15 \mathrm{~cm} \times 15 \mathrm{~cm}$ because the Bee-Bot can move only in $15 \mathrm{~cm}$ increments. For the purposes of this study, the researchers designed and created three different mats, one for Phase 2, another for Phase 3, and one for Phase 4 (see Figure 1).

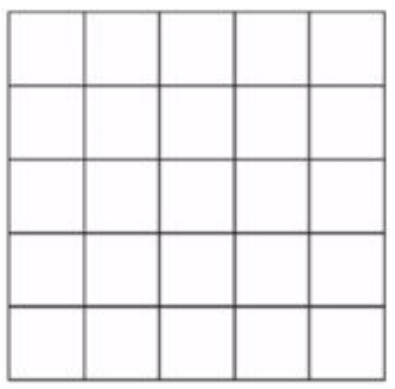

Mat 1 for Phase 2

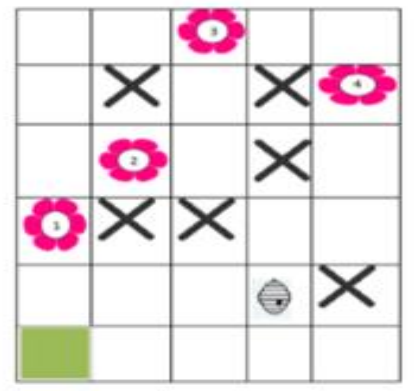

Mat 2 for Phase 3

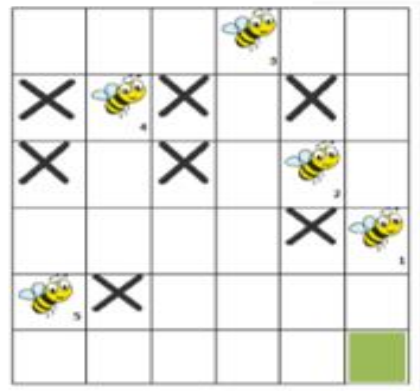

Mat 3 for Phase 4

Figure 1. The three mats used in the research

\subsubsection{Scaffolding Strategies}

Type A scaffolding used a model (a representation of the real mat in reduced size) of the mat and the actual Bee-Bot in order to better facilitate the formation of mental rotations that are so essential for children younger than seven years old. The child thought about the algorithm and with the help of the researcher noted down in a matrix all commands. The matrix was then used as an external memory system that the child used to program the Bee-Bot to run on the real mat. Type B scaffolding provided each child with $5 \mathrm{~cm} \times 5 \mathrm{~cm}$ 
laminated cards of all Bee-Bot commands and each child was asked to use the cards to form a sequence of commands for each problem-solving subtask. Then, the child used this external memory system to program the Bee-Bot and test the algorithm on the real mat.

\subsection{Research Procedures}

During the first phase, the CEFT was administered individually to classify the children to FD or FI participants. On the following day, during Phase 2, the researcher worked with each child individually to demonstrate the Bee-Bot commands. Phase 3 took place a day after Phase 2. During the third phase, the children, in the two scaffolding groups and the Control group, worked with the researcher individually to solve the second problem-solving task. A day after Phase 3, during the fourth phase, the external memory systems were removed and children's performance was assessed with the third problem-solving task.

\section{RESULTS}

\subsection{Computational Thinking Evaluation Rubrics}

The researchers developed inductively, based on students' answers (i.e., sequences of commands) two rubrics for measuring computational thinking. The first rubric assessed children's computational thinking holistically, and the second rubric assessed children's sequencing skills. Regarding the first rubric, the authors first wrote down all attempts the children made for a problem-solving task. For example, X's performance for Subtask2 in Phase 3 was recorded as follows:

X's first attempt (unsuccessful): MOVE BACKWARD-TURN RIGHT

X's second attempt (unsuccessful): MOVE BACKWARD-TURN RIGHT-MOVE FORWARD

X's third attempt (successful): MOVE BACKWARD-TURN RIGHT-TURN RIGHT-MOVE FORWARD

Then, the researchers collected all possible answers from all 180 students for Subtask2 and created a table as follows. Table 2 shows the number of possible attempts children made to solve the task. If for example, the maximum number of attempts made to find the correct answer was 3 , then the max score is 3 for finding the correct answer during the first attempt, two if it took two attempts and one if it took three attempts.

Table 2. Subtask2: Holistic measurement of computational thinking

\begin{tabular}{lll}
\hline Code & Description & Score \\
\hline 3 & Attempt 1- Success & 3 \\
2 & Attempt 2 - Success & 2 \\
1 & Attempt 3 - Success & 1 \\
\hline
\end{tabular}

Similarly, for sequencing, the researchers first wrote down all sequences of commands the learners executed for each attempt made. For Subtask2, as it was presented above, Table 3 was prepared.

Table 3. Subtask2: Measuring the skill of sequencing

\begin{tabular}{lll}
\hline Code & Description & $\begin{array}{l}\text { Points received (one point per } \\
\text { correct command in correct } \\
\text { sequence) }\end{array}$ \\
1 & Attempt 1 - MOVE BACKWARD-TURN RIGHT & 2 \\
2 & Attempt 2 - MOVE BACKWARD-TURN RIGHT-MOVE & 2 \\
& FORWARD & \\
3 & Attempt 3 - MOVE BACKWARD-TURN RIGHT-TURN RIGHT- \\
\hline
\end{tabular}

The total score for sequencing was then calculated as follows: Total_Sequencing_Subtask2 = Sequencing_Subtask2_Attempt1 + Sequencing_Subtask2_Attempt2 + Sequencing_Subtask2_Attempt3 $=2+2+4=8$. 


\subsection{Holistic Computational Thinking and the Skill of Sequencing}

Table 4 presents children's holistic computational thinking scores in Phase 3 for each scaffolding type and FDI. As it is shown, FD and FI children in Scaffolding Type A tended to score higher on the holistic computational thinking assessment than FD and FI children in Scaffolding Type B and the Control group. Also FI learners scored higher in all groups. A 2 X 3 analysis of variance was performed and found that both main effects of FDI $(\mathrm{F}(1,174)=4.54, \mathrm{p}<0.05)$ and type of scaffolding $(\mathrm{F}(2,174)=52.60, \mathrm{p}<0.01)$ were found to be statistically significant in favor of FI children and Scaffolding Type A, respectively. Post-hoc comparisons showed that both Scaffolding Type A and Scaffolding Type B outperformed the Control group. After removing the external memory systems in Phase 4, as Table 4 shows, FI learners outperformed all other learners in all groups. FD learners in Scaffolding Type A scored higher than the FD children in Scaffolding Type B. In order to examine whether these descriptive differences were statistically significant, a 2 X 3 analysis of variance was again performed. It was found that only FDI was a significant main effect $(\mathrm{F}(1,174)=19.38, \mathrm{p}<0.01)$ in favor of the FI children.

Table 4. Descriptive statistics of children's holistic computational thinking in Phase 3 and Phase 4 for each scaffolding type and cognitive type

\begin{tabular}{|c|c|c|c|}
\hline \multicolumn{4}{|c|}{ Phase 3} \\
\hline & Mean & SD & $\mathrm{N}$ \\
\hline \multicolumn{4}{|c|}{ Scaffolding Type A } \\
\hline FD & 234.93 & 48.31 & 30 \\
\hline FI & 249.43 & 9.8 & 30 \\
\hline Total & 241.18 & 35.33 & 60 \\
\hline \multicolumn{4}{|c|}{ Scaffolding Type B } \\
\hline FD & 224.40 & 38.48 & 30 \\
\hline FI & 231.83 & 27.44 & 30 \\
\hline Total & 228.12 & 33.35 & 60 \\
\hline \multicolumn{4}{|c|}{ Control Group } \\
\hline FD & 163.00 & 55.31 & 30 \\
\hline FI & 179.33 & 44.20 & 30 \\
\hline Total & 171.17 & 50.32 & 60 \\
\hline \multicolumn{4}{|c|}{ Phase 4} \\
\hline & Mean & SD & $\mathrm{N}$ \\
\hline \multicolumn{4}{|c|}{ Scaffolding Type A } \\
\hline FD & 165.77 & 63.95 & 30 \\
\hline FI & 207.17 & 34.57 & 30 \\
\hline Total & 186.47 & 55.08 & 60 \\
\hline \multicolumn{4}{|c|}{ Scaffolding Type B } \\
\hline FD & 159.13 & 59.88 & 30 \\
\hline FI & 201.63 & 46.36 & 30 \\
\hline Total & 180.38 & 57.26 & 60 \\
\hline \multicolumn{4}{|c|}{ Control Group } \\
\hline FD & 185.77 & 56.69 & 30 \\
\hline FI & 203.87 & 43.30 & 30 \\
\hline Total & 194.82 & 50.84 & 60 \\
\hline
\end{tabular}


Table 5 presents children's scores on the skill of sequencing in Phase 3 for each scaffolding type and FDI. As it is shown, FD and FI children in Scaffolding Type A outperformed all other learners. Also, the scores between the FD and FI learners in Scaffolding Type A were almost the same. A 2 X 3 analysis of variance was performed and found that only the main effect of scaffolding technique was found to be statistically significant $(\mathrm{F}(2,174)=19.38, \mathrm{p}<0.01)$ in favor of Scaffolding Type A. Post-hoc comparisons showed that both Scaffolding Type A and Scaffolding Type B outperformed the Control group. After removing the external memory systems in Phase 4 FI learners outperformed all other learners in all groups. A 2 X 3 analysis of variance was again performed and found that only FDI was a significant main effect $(\mathrm{F}(1,174)=20.16, \mathrm{p}<0.01)$ in favor of the FI children.

Table 5. Descriptive statistics of children's performance on the sequencing skill in Phase 3 and Phase 4 for each scaffolding type and cognitive type

\begin{tabular}{|c|c|c|c|}
\hline \multicolumn{4}{|c|}{ Phase 3} \\
\hline & Mean & SD & $\mathrm{N}$ \\
\hline \multicolumn{4}{|c|}{ Scaffolding Type A } \\
\hline FD & 494.60 & 48.79 & 30 \\
\hline FI & 494.27 & 40.67 & 30 \\
\hline Total & 494.43 & 44.53 & 60 \\
\hline \multicolumn{4}{|c|}{ Scaffolding Type B } \\
\hline FD & 487.20 & 48.79 & 30 \\
\hline FI & 471.77 & 81.49 & 30 \\
\hline Total & 479.48 & 68.25 & 60 \\
\hline \multicolumn{4}{|c|}{ Control Group } \\
\hline FD & 360.87 & 112.64 & 30 \\
\hline FI & 383.93 & 90.26 & 30 \\
\hline Total & 372.40 & 101.86 & 60 \\
\hline \multicolumn{4}{|c|}{ Phase 4} \\
\hline & Mean & SD & $\mathrm{N}$ \\
\hline \multicolumn{4}{|c|}{ Scaffolding Type A } \\
\hline FD & 301.33 & 88.40 & 30 \\
\hline FI & 370.63 & 55.97 & 30 \\
\hline Total & 335.98 & 81.25 & 60 \\
\hline \multicolumn{4}{|c|}{ Scaffolding Type B } \\
\hline FD & 299.50 & 85.75 & 30 \\
\hline FI & 348.83 & 79.77 & 30 \\
\hline Total & 324.17 & 85.79 & 60 \\
\hline \multicolumn{4}{|c|}{ Control Group } \\
\hline FD & 318.43 & 77.42 & 30 \\
\hline FI & 354.30 & 69.75 & 30 \\
\hline Total & 336.37 & 75.26 & 60 \\
\hline
\end{tabular}




\section{DISCUSSION}

The findings showed that in Phase 3 children in both scaffolding groups outperformed the children in the Control group on the holistic measurement of computational thinking and the skill of sequencing. These results are consistent with previous work by Jonassen (1992) and more contemporary work by Angeli and Valanides (2004b) that showed the necessity of using scaffolding techniques, such as, external memory systems, to facilitate young students' learning with technological tools. However, when the external memory systems were withdrawn during Phase 4, no significant differences were detected between the scaffolding groups and the Control group on the holistic measurement of computational thinking and the skill of sequencing. Only FDI was found to be a statistically significant main effect in Phase 4, indicating that FI children were better in computational thinking than FD learners. This finding is consistent with previous research, which showed that FI learners outperformed the FD learners in self-directed problem-solving tasks and that FD learners needed support and scaffolding to succeed (Angeli \& Valanides, 2004a, 2004b). In conclusion, the findings of this study strongly indicate that FD learners need scaffolding to succeed in problem-solving tasks with robotics and that teachers need to consider learners' cognitive type to ensure that all learners can learn with robots during classroom activities.

\section{REFERENCES}

Armoni, M., and Gal-Ezer, J. 2014. Early computing education: why? what? when? who?. ACM Inroads, Vol. 5, No. 4, pp 54-59.

Angeli, C., and Valanides, N. 2004a. Examining the effects of text-only and textvisual instructional materials on the achievement of field-dependent and field independent learners during problem-solving with modeling software. Educational Technology Research and Development, Vol. 52, No. 4, pp 23-36.

Angeli, C., and Valanides, N. 2004b. The effect of electronic scaffolding for technology integration on perceived task effort and confidence of primary student teachers. Journal of Research on Technology in Education, Vol. 37, No. 1, pp 29-43.

Angeli, C. 2013. Examining the effects of field dependence-independence on learners' problem-solving performance and interaction with a computer modeling tool: Implications for the design of joint cognitive systems. Computers \& Education, Vol.62, pp 221-230.

Angeli, C., and Valanides, N. 2013. Using educational data mining methods to assess field-dependent and field-independent learners' complex problem solving. Educational Technology Research \& Development, Vol.61, No.3, pp 521-548.

Bers, M. U., et al, 2014. Computational thinking and tinkering: Exploration of an early childhood robotics curriculum. Computers \& Education, Vol. 72, pp 145-157.

Chen, S., and Macredie, R. D. 2004. Cognitive modeling of student learning in webbased instructional programs. International Journal of Human-Computer Interaction, Vol.17, No.3, pp 375-402.

Ching, Y. H. et al, 2018. Developing Computational Thinking with Educational Technologies for Young Learners. TechTrends, Vol. 62, pp 1-11.

Evans, C. et al, 2013. Field independence: Reviewing the evidence. British Journal of Educational Psychology,Vol. 83, No.2, pp 210-224.

Grover, S., and Pea, R. 2013. Computational Thinking in K-12: A Review of the State of the Field. Educational Researcher, Vol.42, No. 1, pp 38-43.

Hall, J. K. 2000. Field dependence-independence and computer-based instruction in geography. Unpublished doctoral dissertation, Virginia Polytechnic Institute and State University, Blacksburg, VA.

Jonassen, D. H. 1992. What are cognitive tools?. Cognitive tools for learning pp 1-6. Berlin: Springer.

Karp, S. A., and Konstadt, M. 1971. Children's embedded figures test. Washington: Consulting Psychologists Press.

Kazakoff, E. R. et al,2013. The effect of a classroom-based intensive robotics and programming workshop on sequencing ability in early childhood. Early Childhood Education Journal, Vol. 41, No.4, pp 245-255.

Messick, S. 1987. Structural relationships across cognition, personality, and style. Aptitude, Learning, and Instruction, Vol. 3, pp 35-75.

Shute, R., and Miksad, J. 1997. Computer Assisted Instruction and Cognitive Development in Preschoolers. Child Study Journal, Vol.27, No.3, pp 237-53. 
ISBN: 978-989-8533-93-7 @ 2019

Sullivan, A. et al, 2013. The wheels on the bot go round and round: Robotics curriculum in pre-kindergarten. Journal of Information Technology Education, Vol.12, pp 203-219.

Wing, J. 2006. Computational thinking. Communications of the ACM, Vol.49, No. 3, pp 33-36.

Wing, J. M. 2008. Computational thinking and thinking about computing. Philosophical Transactions of the Royal Society A: Mathematical, Physical and Engineering Sciences, Vol. 366, No.1881, pp 3717-3725.

Witkin, H. A. et al, 1977. Field-dependent and field-independent cognitive styles and their educational implications. ETS Research Bulletin Series, Vol.1975, No.2, pp 1-64. 